\title{
Microbial and Physical Properties of Probiotic Fermented Milk Supplemented with Lentil Flour
}

\author{
Fatemeh Zare \& Valerie Orsat \\ Bioresource Engineering Department \\ McGill University (Macdonald Campus) \\ 21111 Lakeshore Road, Ste.-Anne-de-Bellevue \\ QC H9X 3V9, Canada \\ Claude Champagne \\ Agriculture and Agri-Food Canada, 3600 Casavant Boul \\ West, Saint-Hyacinthe, QC J2S 8E3, Canada \\ Benjamin K. Simpson \\ Food Science \& Agricultural Chemistry Department \\ McGill University (Macdonald Campus) \\ 21111 Lakeshore Road, Ste-Anne-de-Bellevue \\ QC H9X 3V9, Canada \\ Joyce I. Boye (Corresponding author) \\ Agriculture and Agri-Food Canada, 3600 Casavant Boul. West \\ Saint-Hyacinthe, QC J2S 8E3, Canada \\ Tel: 1-450-768-3232Ｅ-mail: joyce.boye@agr.gc.ca
}

Received: September 22, 2011

Accepted: October 13, $2011 \quad$ Published: February 1, 2012

doi:10.5539/jfr.v1n1p94

URL: http://dx.doi.org/10.5539/jfr.v1n1p94

\begin{abstract}
Skim milk $(9.5 \% \mathrm{w} / \mathrm{v}$ solid content) was supplemented with $1-3 \%(\mathrm{w} / \mathrm{v})$ lentil flour or skim milk powder, inoculated with Lactobacillus rhamnosus AD 200 at $37{ }^{\circ} \mathrm{C}$ and stored at $4{ }^{\circ} \mathrm{C}$. Acid production during the fermentation, microbial growth, physical $(\mathrm{pH}$, syneresis, and color) and rheological (dynamic oscillation temperature sweep test at $4-50{ }^{\circ} \mathrm{C}$ ) properties, were studied after production and during 28 days. Milk supplementation with 1-3\% lentil flour enhanced acid production, and the microbial population (CFU) of $L$. rhamnosus was comparable with that of the non-supplemented control after production. After 28 days, the CFU of $2 \%$ and $3 \%$ lentil-supplemented probiotic were as high as $1 \%$ skim milk supplemented sample. All lentil flour-supplemented samples had significantly lower "L" values and higher "b" and "a" values. Probiotic products with 1-3\% lentil flour showed higher storage $\left(G^{\prime}\right)$ and loss $\left(G^{\prime \prime}\right)$ moduli compared with $1-3 \%$ skim milk supplemented samples and the non-supplemented control.
\end{abstract}

Keywords: Lentil, Probiotic, Microbial and physical properties

\section{Introduction}

Probiotics are "live microorganisms which when administered in adequate amounts confer health benefits to the host" (Araya et al., 2002). Indeed, humans have been consuming probiotics in the form of fermented foods for many years (Ranadheera, Baines, \& Adams, 2010). Most common types of probiotics are lactic acid bacteria (LAB), however, probiotics include species from the Lactobacillus, Pediococcus and Bifidobacterium genera. 
Lactobacillus rhamnosus and Bifidobacterium have been the predominant species used as probiotics over the years (Tamime \& Robinson, 1999; Ranadheera et al., 2010).

The health benefits of probiotics have been known for a long time, dating from the very early ages when Hippocrates and other scientists reported that fermented milk could heal certain digestive disorders (Ranadheera et al., 2010). Élie Metchnikoff is, however, considered in recent history to have discovered probiotics (Heller, 2001). He noticed with greater longevity in Caucasian populations who frequently consumed fermented milks and proposed that the acid-producing organisms in fermented dairy products stopped "fouling" in the large intestine, consequently leading to prolongation of a healthy life (Heller, 2001). Probiotics are resistant to bile and survive passage through the gastrointestinal tract without induction of systemic immune or inflammatory reactions. Recent studies have indicated that probiotic bacteria can provide several therapeutic advantages, such as modification of the immune system, blood cholesterol reduction, lessening of lactose intolerance, maintained remission of Crohn's disease, healing of diarrhea, and prevention of infections of uro-genital organs (Hekmat, Soltani, \& Reid, 2009).

Prebiotics, on the other hand, are non-digestible food ingredients that alter the functionality and/or growth of one, or a limited number of probiotic bacteria in the colon (Prado, Parada, Pandey, \& Soccol, 2008). Oligosaccharides such as lactulose, galactooligosaccharides, inulin, fructooligosaccharides, and other food carbohydrates are some well known examples.

There is an obvious potential for a symbiotic effect of probiotics and prebiotics, since prebiotics promote the growth and activities of probiotics. Several studies have shown that growth and viability of $L$. rhamnosus could be increased in the presence of resistant starch, inulin, fructooligosaccharides, polydextrose and oligofructose in fermented food products such as yogurt, fermented milk, cheese and ice cream (Ranadheera et al., 2010). Apart from nutritional benefits of prebiotics, addition of these ingredients provides techno-functional benefits that can improve the various quality parameters of the final products. Some plant-based matrices are very rich in prebiotic compounds and inulin-containing chicory is probably the best example of this. Inulin and oligofructan derived from inulin improve the viscoelastic properties of yogurt and fermented milk products. They have been shown to increase firmness and viscosity and decrease syneresis (Bozanic, Rogelj, \& Tratnik, 2001 and 2002; Dello Staffolo, Bertola, Martino, \& Bevilacqua, 2004; Debon, Prudencio, \& Petrus, 2010; De Castro, Cunha, Barreto, Amboni \& Prudencio, 2008). Several studies have also indicated that the physico-chemical characteristics ( $\mathrm{pH}$, acid production, color and water activity) of fermented products such as yogurt, soy yogurt and probiotic fermented milk products improve due to supplementation with prebiotics such as inulin, resistance starch, fiber and calcium, date fiber, $\beta$-glucan, glucose and raffinose. This could be due to the nutritional benefits of prebiotics in enhancing the growth of probiotics and promoting acid production during fermentation and storage, as well as their techno-functional properties which could enhance the physical properties of the products (Donkor, Nilmini, Stolic, Vasiljevic, \& Shah, 2007; Aportela-Palacois, Sosa-Morales, \& Velez-Ruiz, 2005; Vasiljevic, Kealy, \& Mishra, 2007; Hashim, Khaul, \& Afifi, 2009).

There is great economic interest in finding other prebiotic-rich food matrices. The nutritional composition of lentil which includes complex carbohydrates (e.g., resistant starch, oligosaccharides, sucrose, raffinose, stachyose and verbascose), protein, important vitamins and minerals as well as antioxidants, and only very small amounts of unsaturated fats could make this ingredient a very good source of prebiotic components for human nutrition and probiotics bacteria such as L. rhamnosus (Zare, Boye, Orsat, Champagne, \& Simpson, 2011; Wang, \& Daun, 2004). In a previous study, we showed that yogurt starter culture (S. thermophilus and L. bulgaricus) grow better in milk supplemented with lentil flour and acid production during fermentation and storage improved with the addition of lentil flour. This study expands on our previous studies and explores lentil supplementation of milk in the presence of a specific probiotic species, L. rhamnosus. We investigate the effect of supplementation of fermented milk with 1-3\% lentil flour on acid production during fermentation, growth of $L$. rhamnosus, $\mathrm{pH}$, syneresis, color and rheological properties of the final product immediately after production and during 28 days of storage. For comparison, skim milk as the base media for fermentation with and without supplementation with $1-3 \%$ skim milk powder was similarly analyzed.

\section{Materials and Methods}

\subsection{Cultures and ingredients}

Non-fat skim milk powder used was from Agropur (Quebon brand; St. Laurent, QC, Canada); lentil flour was from K2 Milling Company (Tottenham, ON, Canada); Lactobacillus rhamnosus AD200 was purchased from ABIASA Inc. (St. Hyacinthe, QC, Canada). The cultures were obtained in freeze-dried form, packaged in laminated foils and were stored at $4{ }^{\circ} \mathrm{C}$ until used. Skim milk powder mixed in distilled water $(9.5 \% \mathrm{w} / \mathrm{v})$ 
served as the base for supplementation and is referred to as "control". In two series of experimental assays $1-3 \%(\mathrm{w} / \mathrm{v})$ of lentil flour or $1-3 \%$ of skim milk powder were added separately to the skim milk base (control).

\subsection{Fermentation}

The Lactobacillus rhamnosus AD200 culture contained a microbial concentration of 2 x $1011 \mathrm{CFU} / \mathrm{g}$. It was re-hydrated at $37^{\circ} \mathrm{C}$ in the sterilized skim milk to obtain $2 \times 109 \mathrm{CFU} / \mathrm{mL}$. Subsequently $1 \mathrm{~mL}$ of this dilution was added to $100 \mathrm{~mL}$ media which represented an inoculation level of approximately $2 \times 107 \mathrm{CFU} / \mathrm{mL}$. The experimental protocol used for probiotic supplementation and production are shown in Figure 1. Acidification trend in fermented milk by L. rhamnosus was measured during fermentation according to the method described by De Brabandere and De Baerdemaeker (1999) using a FACS (Fermentation Acquisition and Control System) installed in a Forma Scientific (OH, US) programmable incubator.

\subsection{Product characterization}

The buffering capacity of the different blends was estimated by acid titration and $\mathrm{pH}$ measurements using a $\mathrm{pH}$ meter (Accumet AP61, Fisher Scientific Inc, ON, Canada) and a $50 \mathrm{~mL}$ digital burette (Brinkmann Instruments Ltd., ON, Canada). For viable counts culture media; MRS agar from Difco Company (KS, USA) was used for quantifying the L. rhamnosus. Viable counts were obtained after 48 hours incubation at $37^{\circ} \mathrm{C}$ under anaerobic conditions.

$\mathrm{pH}$ was measured in the probiotic fermented milk using a $\mathrm{pH}$ meter (Accumet AP61, Fisher Scientific Inc, ON, Canada).

Syneresis was determined as the amount of spontaneous whey separation from the fermented product according to the method described by Lucey, Munro and Singh (1998), with some modifications. The volume of whey drained from $100 \mathrm{~mL}$ of undisturbed set yogurt prepared in cylindrical tubes was measured and reported as percentage syneresis.

Color was determined as lightness (L), red/greenness (a), and yellow/blueness (b), using a colorimeter (Konica Minolta, CM-503 c, NJ, US).

Dynamic oscillation tests were conducted to determine the flow behaviour and characterize the viscoelastic properties of the yogurt, using a rheometer (TA Instruments, SR-2000, DE, US) fitted with a 40-mm-diameter cone and 0.04 radian degree cone angle and plate geometry with a $4 \mathrm{~mm}$ gap. To ascertain the applicable stress and frequency in which storage modulus (G') and loss modulus ( $\left.G^{\prime \prime}\right)$ parameters of yogurt would demonstrate a linear constant rate, dynamic frequency ramp tests (frequency from 1 to $10 \mathrm{~Hz}$ and stress set at $3 \mathrm{~Pa}$ ) and dynamic stress ramp tests (stress from 1 to $10 \mathrm{~Pa}$ and frequency set as $2.5 \mathrm{~Hz}$ ) were conducted at $25{ }^{\circ} \mathrm{C}$. Dynamic temperature ramp tests were done at a stress and frequency of $3.0 \mathrm{~Pa}$ and $2.0 \mathrm{~Hz}$, respectively, in a temperature range of 4 to $50{ }^{\circ} \mathrm{C}$ (heating) and 50 to $4{ }^{\circ} \mathrm{C}$ (cooling), at a rate of $10{ }^{\circ} \mathrm{C} / \mathrm{min}$. Aliquots of the samples were carefully removed from the undisturbed yogurt cup and placed on the center of the rheometer plate; the top plate was slowly lowered on the top of the sample prior to analysis.

Viable counts, $\mathrm{pH}$, syneresis, color and rheological parameters were measured after fermentation as well as during 28 days storage at $4{ }^{\circ} \mathrm{C}$ at 7 days interval.

\subsection{Statistical analysis}

Statistical test was conducted using ANOVA analysis (SAS 9.1, SAS Institute Inc. NC, US). Comparisons were made using the Student-Newman-Keuls test and the two sample t-test for comparison of two means.

\section{Results and Discussion}

\subsection{Acidification by L. rhamnosus}

Acidification pattern of the samples after inoculation with L. rhamnosus is presented in Figure 2. For both skim milk powder and lentil flour, supplementation enhanced the acidification rate. The difference in $\mathrm{pH}$ between the supplemented sample and the control became statistically significant after 8 hours of incubation. After 8 hours, the $\mathrm{pH}$ in the $2 \%$ and $3 \%$ skim milk-supplemented products was significantly $(\mathrm{P}<0.05)$ lower than the lentil flour-supplemented media. However, after 12 hours of incubation, the $2 \%$ and $3 \%$ lentil flour-supplemented samples had the lowest $\mathrm{pH}$. As a result, the products with lentil flour reached a $\mathrm{pH}$ of 4.5 significantly earlier than skim milk-supplemented and control sample (Figure 2). This constitutes important time and energy savings in the manufacturing process. These data confirm our preliminary study (Zare, Champagne, Simpson, Orsat, \& Boye, 2012). As milk has greater buffering capacity in comparison with lentil flour (Table 1), the greater acidification rates in products supplemented with lentil flour could have been partially due to their lower 
buffering capacity when compared to the corresponding skim milk-supplemented probiotic products. This, however, does not appear to be the case when the data for lentil flour is compared to the control. Acid production in the media, which is mainly due to lactic acid, is often linked to the growth of lactic acid bacteria (i. e: L. rhamnosus) (Tamime \& Robinson, 1999). The acidification data (especially for the control and lentil flour-supplemented samples), therefore, suggests that growth of the microorganism in the lentil flour-supplemented samples was likely stimulated by the lentil flour. Although, viable counts were not followed during the fermentation to assess this hypothesis, further analyses were carried out after production as well as during storage as shown below.

\subsection{Microbial growth and survival in the supplemented products after production and during storage}

There is no universally accepted number of viable cells required to obtain a health benefit (Reid, 2008). In yogurt products, in order to provide health benefits targeted towards lactose digestion using probiotics, a minimum of $108 \mathrm{CFU}$ per serving is required (EFSA, 2010). Canadian legislation (CFIA, 2009) allows limited non-strain linked claims if the product contains a billion viable cells per portion, and there is a trend, at least in Canada, towards this CFU level in yogurt and probiotic fruit juices available on the market. To maintain these numbers, it is important to follow the probiotics viability during manufacture and storage (Damin, Minowa, Alcântara, \& Oliveira, 2006).

Viable counts of L. rhamnosus in fresh (day 0) products supplemented with lentil flour or skim milk powder varied from $\log 8.11$ to $\log 8.71$ (Table 2). Although important CFU reductions occurred in some samples after 28 days of storage, all samples supplied the minimum 1 billion per portion amount of probiotics required for a non-strain related health claim (CFIA, 2009), presuming a portion to represent about $100 \mathrm{~mL}$. Furthermore, many had the $10^{8} \mathrm{CFU} / \mathrm{mL}$ threshold required to market the high-density probiotic products such as DanActive $^{\mathrm{TM}}$ (Danone) or BioBest MaximmunitéTM (Parmalat), which contain 10 billion CFUs per portion. These counts are, however, lower than those obtained for L. rhamnosus in fruit-based media, which were well above $10^{9} \mathrm{CFU} / \mathrm{mL}$ (Champagne and Gardner, 2008). Growth and acidification of L. rhamnosus in milk is rather slow (Gaudreau, Champagne, \& Jelen, 2005), and low CFU counts in milk-based products are also encountered with other probiotic cultures (Champagne, Tompkins, Buckley, \& Green-Johnson, 2010). Therefore, the data on growth and acidification with L. rhamnosus in milk is in line with that of the literature. Supplementation with 1 to 3\% skim milk powder significantly improved L. rhamnosus CFU levels in the fresh products (Table 2).

Addition of 2 and 3\% lentil flour also increased CFU counts in the fresh products (Table 2). The high CFUs in the fresh supplemented milk powder and lentil flour samples remained higher than the control treatment during the 28 days of cold storage (Table 2). Interestingly, although the addition of lentil flour accelerated the rate of acidification, it did not increase the CFU values in the fermented probiotic products (Table 2) as much as the skim milk powder-supplemented samples.

The nature of the stimulatory factors in lentil flour, thus, remains unknown and it is hypothesized that lentil flour could serve as a prebiotic source due to its nutrients components such as protein, resistant starch, sucrose, raffinose, stachyose, verbascose and oligosaccharides for L. rhamnosus in probiotic products (Wang \& Daun, 2004). Also, supplementation with lentil flour significantly maintained the stability of the L.rhamnosus during storage (Table 2).

Antioxidants (Dave \& Shah, 1997) and carbohydrates (Silva, Carvalho, Pereira, Teixeira, \& Gibbs, 2004) have been shown to improve the stability of lactobacilli during storage. It remains to be determined which compounds in the lentil flour have this protective benefit towards the lactobacilli.

A regression analysis was carried out to ascertain the role of the buffering capacity of the ingredients (Table 1) on the viable counts obtained at the end of the fermentation (Table 2). There was a positive correlation $\left(\mathrm{R}^{2}=\right.$ 0.79 ) between the CFU data after fermentation and the buffering capacity of the skim milk supplementation samples. Also, there is a positive correlation $\left(\mathrm{R}^{2}=0.88\right)$ between the CFU data after fermentation and the buffering capacity of the lentil flour-supplemented samples. This high correlation data suggest that, for $L$. rhamnosus AD200, the buffering capacity is a strong regulator of growth, in both skim milk and lentil flour at this range of milk solids. Thus, the very different nutritive content of milk and lentil flour had a negligible effect on final CFU levels when added to milk in the 1-3\% supplementation range. The importance of the buffering capacity and biomass levels is in agreement with the literature (Badran \& Reichart, 1994). However, data on acidification rates showed a different picture. One would expect that the higher buffering capacity would slow the rate of $\mathrm{pH}$ reduction. A regression analysis between $\mathrm{pH}$ values at time $=18 \mathrm{~h}$ (hour) and the buffering capacity of the media showed absolutely no correlation $\left(\mathrm{R}^{2}<0.01\right)$. Therefore the acidification rate itself is completely independent of the buffering capacity of the ingredients, and is presumably directly linked to the 
nutrient content. It can be concluded, however, that the nutrients brought by lentil flour accelerated the acidification rate of L. rhamnosus AD200 much more than that of skim milk.

\subsection{Change in $\mathrm{pH}$ during storage}

The $\mathrm{pH}$ reduction is due to the acid produced by L. rhamnosus during fermentation which continues slightly during storage. In all samples, the $\mathrm{pH}$ decreased by 0.1 to 0.5 units over the 28 days storage period (Table 2). This drop in $\mathrm{pH}$ was greater in products supplemented with 1-3 \% lentil flour in comparison with 1-3\% skim milk-supplemented and control samples. The level of skim milk supplementation did not affect the $\mathrm{pH}$ reduction after 28 days of storage $(\mathrm{P}<0.05)$. However, this was not the case in products containing the lentil flour. Indeed, the $\mathrm{pH}$ in the $3 \%$ lentil-supplemented product was more stable during storage (Table 2) than the products containing $1-2 \%$ lentil flour, and this difference actually became statistically significant $(\mathrm{P}<0.05)$ after 14 days of storage (data not presented). It was examined if there was a link between these $\mathrm{pH}$ data and that from buffering capacity or viable counts (Table 1). No correlation was found between the $\mathrm{pH}$ at the end of storage and the buffering capacity of the medium $(\mathrm{R} 2<0.1)$ nor with the viable counts at the beginning of storage $(\mathrm{R} 2=0.26)$. These data are in line with other studies which show that acidification during storage does not necessarily parallel CFU counts (Seo, Lee, Chang, \& Kwak, 2009). According to Kailasapathy, Harmstorf, \& Phillips, 2008, the higher the buffering capacity of the media, the smaller the change in $\mathrm{pH}$ due to changes in acid content of the food system. This was not the case in our study; the skim milk control had the lowest buffering capacity (Table 1) but was the product having the most stable $\mathrm{pH}$ during storage (Table 2). Supplementation with lentil flour, therefore, seems to increase the acidifying ability of the lactobacilli during storage.

There was a concern with respect to the stability of the probiotics during storage, because a higher buffering capacity of the medium tends to increase the survival of live culture bacteria (Kailasapathy et al., 2008). This was not a problem in this study. Indeed, the viable counts in the lentil flour-supplemented products dropped on average by $0.3 \log \mathrm{CFU} / \mathrm{g}$ while that of the skim milk-supplemented samples had viability losses of approximately 0.5 by $\log$ CFU/g (Table 2). Although, the increased acidification rates during storage did not negatively affect the losses in viability, $\mathrm{pH}$ is known to affect texture. Therefore, analyses of color and texture were carried out on the fresh products as well as on the stored ones.

\subsection{Color}

Color is one of the most important factors for marketability of food products and consumer acceptance. Although a probiotic product could provide several health benefits to consumers, they will not be marketable if consumers do not find them to be visually appealing.

The color of lentil flour-supplemented probiotic product should, therefore, be comparable to non-supplemented or skim milk-supplemented probiotic or other fermented dairy products. Furthermore, the color of the supplemented products should ideally remain unchanged after production and during storage. Figure 3 ( $\mathrm{a}, \mathrm{b}$ and c), shows differences in the color ( $\mathrm{a}, \mathrm{b}$ and $\mathrm{L}$ values) of the 1-3\% lentil flour and 1-3\% skim milk-supplemented and control probiotic beverages at day 1 and 28 days after production. On the first day of production all lentil flour-supplemented samples had significantly lower " $L$ " value and higher "a" and "b" values in comparison with the other samples. Also, the level of supplementation significantly affected the "L" and "b" values in skim milk-supplemented samples, but for lentil flour-supplemented samples, the level of supplementation only affected the "b" values $(P<0.05)$. After 28 days, the "L" values for the lentil-supplemented probiotic beverage samples decreased less than the "L" values for the skim milk-supplemented samples; this means that the skim milk-supplemented probiotic beverages became darker during storage significantly more than the lentil flour-supplemented samples. However, after 28 days of storage, the 3\% lentil flour-supplemented sample had the lowest " $\mathrm{L}$ " value and the highest "a" and "b" values in comparison with the other samples $(P<0.05)$. " $\mathrm{L}$ " value represents lightness (100) and blackness (0); "a" represents red (+ve) to green (-ve) hues, whereas "b" represents yellow (+ve) to blue (-ve) hues (Sanz, Salvador, Jimenez, \& Fiszman, 2008); thus, the color measurements indicate that immediately after production the lentil flour-supplemented yogurt were darker and had less greenness and more yellowness hues in comparison with the skim milk-supplemented samples. After 28 days, the $1-2 \%$ lentil flour-supplemented probiotic beverages were comparable to the $2 \%$ skim milk-supplemented and control samples, in terms of lightness.

\subsection{Syneresis}

Acid production due to growth of L. rhamnosus during fermentation, results in lowering of the $\mathrm{pH}$ to the isoelectric point of casein (4.5), which results in protein coagulation and gel formation. Syneresis provides an indication of the non-homogeneities in the gel system; thus, higher water separation (syneresis) is related to gel instability (Lucey et al., 1998). Figure 4 shows the syneresis of lentil flour and skim milk-supplemented 
probiotic and control beverage samples immediately after production and after 14 and 28 days of storage. On day 1 , the $1-3 \%$ lentil flour showed the lowest syneresis, which was significantly lower than for the $1-3 \%$ skim milk-supplemented and control samples $(\mathrm{P}<0.05)$. The level of supplementation affected syneresis in lentil flour-supplemented samples (i.e., the higher the supplementation level, the lower the syneresis), whereas this factor had a lesser effect on skim milk-supplemented samples. After 14 days of storage, although the volume of liquid separated from the gel dramatically increased in the 2-3\% lentil flour-supplemented samples, the 3\% lentil flour-supplemented sample still showed the least syneresis compared to all other samples $(\mathrm{P}<0.05)$. Most of the increase in syneresis occurred between days 1 and 14 of storage.

It is hypothesized that the greater changes in syneresis in lentil flour supplemented samples were potentially due to the greater decrease in $\mathrm{pH}$. Indeed, acidification during storage was highest in the lentil flour-supplemented products (Table 2) and this parameter is directly linked to syneresis (Tamime \& Robinson, 1999).

Supplementation of probiotic products with an increase in the total solid content, especially protein content, results in stronger texture and less whey separation (Peng, Serra, Horne, \& Lucey, 2009). This may explain the lowest syneresis in the 3\% lentil flour and 3\% skim milk-supplemented samples. Also, considering the starch and fiber contents of lentil flour, which have hydrocolloidal properties, it could be suggested that lentil flour confers a more homogenous texture to the samples in comparison with skim milk powder.

\subsection{Rheological properties}

Rheometry is a practical technique for measuring the textural properties of foods. Viscoelastic property measurements give knowledge of the rheological characteristics of foods and can help to give an assessment of the initial experience of a consumer (Kealy, 2006). Oscillatory tests have been used to assess the rheological properties of fermented milk products in several studies (Ozer, Robinson, Grandison, \& Bell, 1997; Remeuf, Mohammed, Sodini, \& Tissier, 2003; Sodini, Lucas, Tissier, \& Corrieu, 2005). When a product is taken out of the refrigerator for consumption and then stored again, the rheological properties could be expected to change. Dynamic temperature ramp test allows the study of the rheological properties during heating and cooling processes.

Results of storage modulus $\left(\mathrm{G}^{\prime}\right)\left(\right.$ elasticity) and loss modulus $\left(\mathrm{G}^{\prime \prime}\right)(\mathrm{viscosity})$ as a function of temperature for the $1-3 \%$ lentil flour-supplemented, 1-3\% skim milk-supplemented and control probiotic samples at days 1, 14 and 28 of storage are presented in Figures 5, 6 and 7. According to the results, G' and G" parameters followed a hysteresis loop during heating and cooling and decreased with increasing temperature and increased back with decreasing temperature in all samples, both after production and during storage. Also, over the range of temperatures studied all supplemented and control samples demonstrated a predominantly elastic behaviour $\left(G^{\prime}>G^{\prime \prime}\right)$.

Furthermore, as the level of supplementation increased, either with skim milk powder or lentil flour, the values of G' and G" both after production and during storage increased. Thus, both the supplementation level and total solids content may be important factors which alter gel structure in probiotic beverage products. This finding is in agreement with others reported in the literature (Sendra et al., 2010).

Additionally, when comparing the responses at certain temperatures during heating and cooling, the lentil flour-supplemented probiotic samples behaved differently from the skim milk-supplemented yogurt. Although both G' and G" values decreased as a result of heating and subsequent cooling for all samples, the reduction for the lentil flour-supplemented samples was not as big as that in the skim milk-supplemented and control samples. In other words, the gel structure, especially for the $1 \%$ and $2 \%$ skim milk-supplemented probiotic samples, almost collapsed since G' and G' values were close to zero during the cooling process (from $50-4{ }^{\circ} \mathrm{C}$ ).

This suggests that the gel structure in the lentil flour-supplemented probiotic samples were more stable under temperature stress conditions than the skim milk supplemented probiotic beverages. This appears in line with the data on syneresis, where supplementation with lentil flour improved the water-binding property of the gel.

\section{Conclusion}

This study showed that supplementation of probiotic beverages with 1-3\% lentil flour results in a significantly faster lowering of the $\mathrm{pH}$ than $1-3 \%$ skim milk powder, suggesting that the fermentation process was significantly faster in 1-3\% lentil-supplemented probiotic samples. This may partially be attributed to the lower buffering capacity of lentil flour, as compared to skim milk as well as to the nutrient enrichment. Indeed, the viable counts of L. rhamnosus in the fermented products enriched by the lentil flour were higher than the non-supplemented control sample, for the same final $\mathrm{pH}$ level $(\mathrm{pH}=4.5)$. The stability of $\mathrm{L}$. rhamnosus during storage at $4{ }^{\circ} \mathrm{C}$ for 28 days in lentil-supplemented samples was at least as good as for the skim 
milk-supplemented probiotic samples. Our results also showed that probiotic supplementation with 1-3\% lentil flour improved the physical and rheological properties of the products in terms of their viscoelastic properties and syneresis and they minimally altered the color of the samples in comparison with the $1-3 \%$ skim milk-supplemented and control probiotic samples after production and during storage. The $\mathrm{pH}$ in the 1-3\% lentil-supplemented probiotic sample was lower than for the 1-3\% skim milk-supplemented samples after 28 days storage, which could not solely be attributed to the lower buffering capacity of the lentil-supplemented media. In terms of syneresis, after 28 days of storage, lentil flour-supplemented probiotic samples had lower syneresis than the corresponding skim milk powder supplemented-products. At any given level of supplementation, the G' and G" value of the lentil flour-supplemented probiotic samples were higher than the values for the skim milk-supplemented probiotic and control sample. The higher G' and G' values may be due to a stronger gel structure attributable to the high fiber and complex carbohydrate content of lentil flour.

Overall, on the basis of the microbial, physico-chemical and rheological properties investigated, the results suggest that lentil flour could be potentially considered as a source of prebiotic and texture improvement ingredient for use in the production of L. rhamnosus fermented milk products.

\section{Acknowledgements}

The study was supported with funds from Pulse Canada and the Agriculture and Agri-Food Canada Agricultural Bio-products Innovation Program. Gratitude is expressed to Yves Raymond and Sabine Ribéreau for technical assistance.

\section{References}

Aportela-Palacois, A., Sosa-Morales, M. E., \& Velez-Ruiz, J. F. (2005). Rheological and physicochemical behavior of fortified yogurt, with fiber and calcium. Journal of Texture Studies, 36 (3), 333-349. http://dx.doi.org/10.1111/j.1745-4603.2005.00020.x

Araya, M., Morelli, L., Reid, G., Sanders, M. E., Stanton, C., Pineiro, M., \& Ben Embarek, P. (2002). Guidelines for the Evaluation of Probiotics in Food - Joint FAO/WHO Working Group. FAO/ WHO, Ontario, Canada.

Badran, I. I., \& Reichart, O. (1994). Comparative study on some fermentation properties of Streptococcus thermophilus and Lactobacillus acidophilus in milk and modified milk media. Part II. Effect of the increased solid not fat on the fermentation properties of the mixed culture. Acta Alimentaria, 23, 133-146.

Bozanic, R., Rogelj, I., \& Tratnik, L. J. (2001). Fermented acidophilus goat's milk supplemented with inulin: comparison with cow's milk. Milchwissenschaft, 56, 618-622.

Bozanic, R., Rogelj, I., \& Tratnik, L. J. (2002). Fermentation and storage of probiotic yogurt from goat milk, Mijekarstvo, 52 (2), 93-111.

Canadian Food Inspection Agency. (2009). Probiotic claims. http://www.inspection.gc.ca/english/fssa/labeti/guide/ch8ae.shtml. (Chapter 8).Section 8.7.

Champagne, C. P., \& Gardner, N. J. (2008). The growth and recovery of an exopolysaccharide-producing Lactobacillus rhamnosus culture on growth media containing apple juice or molasses. Journal of General and Applied Microbiology, 54, 237-241. http://dx.doi.org/10.2323/jgam.54.237

Champagne, C. P., Tompkins, T. A., Buckley, N. D., \& Green-Johnson J. M. (2010) Effect of fermentation by pure and mixed cultures of Streptococcus thermophilus and Lactobacillus helveticus on isoflavone and vitamin content of a fermented soy beverage. Food Microbiology, 27, 968-972. http://dx.doi.org/10.1016/j.fm.2010.06.003

Damin, M. R., Minowa, E., Alcântara, M. R., \& Oliveira, M. N. (2006). Chemical and viability changes during fermentation and cold storage of fermented milk manufactured using yogurt and probiotic bacteria, IUFoST.

Dave, R. I., \& Shah, N. P. (1997). Effectiveness of ascorbic acid as an oxygen scavenger in improving viability of probiotic bacteria in yoghurts made with commercial starter cultures. International Dairy Journal, 7, 435-443. http://dx.doi.org/10.1016/S0958-6946(97)00026-5

De Brabandere, A., \& De Baerdemaeker, J. G. (1999). Effects of process conditions on the pH development during yogurt fermentation, Journal of Food Engineering, 41, 221-227. http://dx.doi.org/10.1016/S0260-8774(99)00096-5

De Castro, F. P., Cunha, T. M., Barreto, P. L. M., Amboni, R. D. D. M. C., \& Prudencio, E. S. (2008). Effect of oligofructose incorporation on the properties of fermented probiotic lactic beverages. International Journal of Dairy Technology, 62, 68-74. http://dx.doi.org/10.1111/j.1471-0307.2008.00447.x 
Debon, J., Prudencio, E. S., \& Petrus, J. C. C. (2010). Rheological and physico-chemical characterization of prebiotic microfiltered fermented milk. Journal of Food Engineering, 99 (2), 128-135. http://dx.doi.org/10.1016/j.jfoodeng.2010.02.008

Dello Staffolo, M., Bertola, N., Martino, M., \& Bevilacqua, A. (2004). Influence of dietary fiber addition on sensory and rhelogical properties of yoghurt. International Dairy Journal, 14, 263-268. http://dx.doi.org/10.1016/j.idairyj.2003.08.004

Donkor, O. N., Nilmini, S. L. I., Stolic, P., Vasiljevic, T., \& Shah, N. P. (2007). Survival and activity of selected probiotic organisms in set-type yoghurt during cold storage. International Dairy Journal, 17, 657-665. http://dx.doi.org/10.1016/j.idairyj.2006.08.006

EFSA (2010). Panel on Dietetic Products, Nutrition and Allergies (NDA); Scientific Opinion on the substantiation of health claims related to Yoghurt cultures and improving lactose digestion (ID 1143, 2976) pursuant to Article 13(1) of Regulation (EC) No 1924/2006. EFSA Journal, 8(10), 1763. Available online: www.efsa.europa.eu/efsajournal.htm

Gaudreau, H., Champagne, C. P., \& Jelen, P. (2005). The use of crude cellular extracts of Lactobacillus delbrueckii ssp. bulgaricus 11842 to stimulate growth of a probiotic Lactobacillus rhamnosus culture in milk. Enzyme and Microbial Technology, 36, 83-90. http://dx.doi.org/10.1016/j.enzmictec.2004.06.006

Hashim, I. B., Khalili, A. K., \& Afifi, H. S. (2009). Quality characteristics and consumer acceptance of yogurt fortified with date fiber. Journal of Dairy Science, 92, 5403-5407. http://dx.doi.org/10.3168/jds.2009-2234

Hekmat, S., Soltani, H., \& Reid, G. (2009). Growth and survival of Lactobacillus reuteri RC-14 and Lactobacillus rhamnosus GR-1 in yogurt for use as functional food. Innovative Food Science and Emerging Technologies, 10, 293-296. http://dx.doi.org/10.1016/j.ifset.2008.10.007

Heller,K. J. (2001). Probiotic bacteria in fermented foods: product characteristics and starter organisms. American Journal of Clinical Nutrition, 73, 374S-9S.

Kailasapathy, K., Harmstorf, I., \& Phillips, M. (2008), Survival of Lactobacillus acidophilus and Bifidobacterium animalis ssp. lactis in stirred fruit yogurts. LWT- Food Science and Technology. 41(7), 1317-1322.

Kealy, T. (2006). Application of liquid and solid rheological technologies to the textural characterisation of semi-solid foods. Food Research International, 39(3), 265-276. http://dx.doi.org/10.1016/j.foodres.2005.07.016

Lucey, A. J. (2001). The relationship between rheological parameters and whey separation in milk gel. Food Hydrocolloids, 15, 603-608. http://dx.doi.org/10.1016/S0268-005X(01)00043-1

Lucey, J. P., Munro, P. A., \& Singh, H. (1998). Whey separation in acid skim milk gels made with Glucono- $\delta$-Lacton: Effects of heat treatment and gelation temperature. Journal of Texture Studies, 29, 413-426. http://dx.doi.org/10.1111/j.1745-4603.1998.tb00813.x

Ozer, B. H., Robinson, R. K., Grandison, A. S., \& Bell, A. E. (1997). Comparison of techniques for measuring the rheological properties of labneh (concentrated yogurt). International Journal of Dairy Technology, 50(4), 129-133. http://dx.doi.org/10.1111/j.1471-0307.1997.tb01753.x

Peng, Y., Serra, M., Horne, D. S., \& Lucey, J. A. (2009). Effect of fortification with various types of milk protein on the rheological properties and permeability of non-fat set yogurt. Journal of Food Science, 74 (9), C666-C673. http://dx.doi.org/10.1111/j.1750-3841.2009.01350.x

Prado, F. C., Parada, J. L., Pandey, A, \& Soccol, C. R. (2008). Trends in non-dairy probiotic beverages. Food Research International, 41, 111-123. http://dx.doi.org/10.1016/j.foodres.2007.10.010

Ranadheera, R. D. C. S., Baines, S. K., \& Adams, M. C. (2010). Importance of food in probiotic efficacy. Food Research International, 43, 1-7. http://dx.doi.org/10.1016/j.foodres.2009.09.009

Reid, G. (2008). Probiotics and prebiotics - Progress and challenges. International Dairy Journal, 18, 969-975. http://dx.doi.org/10.1016/j.idairyj.2007.11.025

Remeuf, F., Mohammed, S., Sodini, I., \& Tissier, J. P. (2003). Preliminary observations on the effects of milk fortification and heating on microstructure and physical properties of stirred yogurt. International Dairy Journal, 13(9), 773-782. http://dx.doi.org/10.1016/S0958-6946(03)00092-X

Sanz, T., Salvador, A., Jimenez, A., \& Fiszman, S. A. (2008). Yogurt enrichment with functional asparagus fibre. Effect of fibre extraction method on rheological properties, colour, and sensory acceptance. European Food Research Technology, 227, 1515-1521. http://dx.doi.org/10.1007/s00217-008-0874-2 
Sendra, E., Kuri, V., Fernandez-Lopez, J., Sayas-Barbera, E., Navarro, C., \& Perez-Alvarez, J. A. (2010). Viscoelastic properties of orange fiber enriched yogurt as a function of fiber dose, size and thermal treatment. Food Science and Technology, 43, 708-714.

Seo, M. H., Lee, V, Chang, Y. H., \& Kwak, H. S. (2009), Physicochemical, microbial, and sensory properties of yogurt supplemented with nano-powdered chitosan during storage, Journal of Dairy Science, 92,5907-5916. http://dx.doi.org/10.3168/jds.2009-2520

Silva, J., Carvalho, A. S., Pereira, H., Teixeira, P., \& Gibbs, P. A. (2004). Induction of stress tolerance in Lactobacillus delbrueckii ssp. bulgaricus by the addition of sucrose to the growth medium. Journal of Dairy Research, 71, 121-125. http://dx.doi.org/10.1017/S0022029903006411

Sodini, I., Lucas, A., Tissier, J. P., \& Corrieu, G. (2005). Physical properties and microstructure of yogurts supplemented with milk protein hydrolysates. International Dairy Journal, 15(1), 29-35. http://dx.doi.org/10.1016/j.idairyj.2004.05.006

Tamime, A.Y., \& Robinson, R.K. (1999). Yogurt: science and technology, Wood head publishing Ltd., (third edition).

Vasiljevic, T., Kealy, T., \& Mishra, V. K. (2007). Effects of beta-glucan addition to a probiotic containing yogurt. Journal of Food Science, 72(7), C405-C411. http://dx.doi.org/10.1111/j.1750-3841.2007.00454.x

Wang, N., \& Daun, J. K. (2004). The Chemical Composition and Nutritive Value of Canadian Pulses Canadian Grain Commission, Grain Research Laboratory, 12-13.

Zare, F., Boye, J. I., Orsat, V., Champagne, C. P., \& Simpson, B. K. (2011). Microbial, physical and sensory properties of yogurt supplemented with lentil flour. Food Research International, 44(8), 2482-2488. http://dx.doi.org/10.1016/j.foodres.2011.01.002

Zare, F., Champagne, C. P, Simpson, B. K., Orsat, V., \& Boye, J. I., (2012). Growth of starter microorganisms and acidification trend in yogurt and probiotic media supplemented with pulse ingredients. LWT - Food Science and Technology, 45, 155-160.

Table 1. Amount of $\mathrm{HCl}(1 \mathrm{M})$ required to acidify $100 \mathrm{~mL}$ of $1-3 \%$ lentil flour and 1-3\% skim milk from $\mathrm{pH}$ 6.5 to 4.0 (SM: skim milk, LF: lentil flour; means followed by the same letter are not significantly different $(P<$ $0.05))$

\begin{tabular}{|l|l|}
\hline \multirow{2}{*}{ Sample } & Titrable $\mathrm{HCl}(\mathrm{mL})$ \\
\cline { 2 - 2 } & Average $\pm \mathrm{SD}$ \\
\hline $1 \% \mathrm{SM}$ & $6.84 \pm 0.00 \mathrm{~b}$ \\
\hline $2 \% \mathrm{SM}$ & $7.58 \pm 0.07 \mathrm{c}$ \\
\hline $3 \% \mathrm{SM}$ & $9.14 \pm 0.00 \mathrm{~d}$ \\
\hline $1 \% \mathrm{LF}$ & $6.51 \pm 0.01 \mathrm{a}$ \\
\hline $2 \% \mathrm{LF}$ & $6.83 \pm 0.21 \mathrm{~b}$ \\
\hline $3 \% \mathrm{LF}$ & $7.06 \pm 0.03 \mathrm{~b}$ \\
\hline Control & $6.38 \pm 0.00 \mathrm{a}$ \\
\hline
\end{tabular}

Table 2. Effect of milk supplementation with skim milk powder (SM) or lentil flour (LF), on viable count of $L$. rhamnosus and $\mathrm{pH}$ after fermentation and during 28 days of storage at $4{ }^{\circ} \mathrm{C}$

\begin{tabular}{|l|l|l|l|l|l|l|l|}
\hline \multirow{2}{*}{ Medium } & \multicolumn{4}{l}{ L. rhamnosus (Log CFU/mL) } & pH \\
\cline { 2 - 8 } & Day 0 & Day 7 & Day 14 & Day 21 & Day 28 & Day 0 & Day 28 \\
\hline $1 \%$ SM & $8.44 \mathrm{c}$ & $8.28 \mathrm{~b}$ & $8.22 \mathrm{~b}$ & $8.00 \mathrm{bc}$ & $7.96 \mathrm{bc}$ & $4.57 \mathrm{~b}$ & $4.44 \mathrm{a}$ \\
\hline $2 \% \mathrm{SM}$ & $8.55 \mathrm{~b}$ & $8.51 \mathrm{a}$ & $8.28 \mathrm{~b}$ & $8.04 \mathrm{~b}$ & $8.02 \mathrm{~b}$ & $4.51 \mathrm{~d}$ & $4.42 \mathrm{a}$ \\
\hline $3 \% \mathrm{SM}$ & $8.71 \mathrm{a}$ & $8.58 \mathrm{a}$ & $8.35 \mathrm{a}$ & $8.21 \mathrm{a}$ & $8.15 \mathrm{a}$ & $4.53 \mathrm{~cd}$ & $4.42 \mathrm{a}$ \\
\hline $1 \% \mathrm{LF}$ & $8.15 \mathrm{de}$ & $8.03 \mathrm{~d}$ & $8.00 \mathrm{~cd}$ & $7.88 \mathrm{~d}$ & $7.83 \mathrm{~d}$ & $4.53 \mathrm{~cd}$ & $4.00 \mathrm{c}$ \\
\hline $2 \% \mathrm{LF}$ & $8.21 \mathrm{~d}$ & $8.14 \mathrm{c}$ & $8.03 \mathrm{c}$ & $7.94 \mathrm{~cd}$ & $7.92 \mathrm{c}$ & $4.55 \mathrm{cb}$ & $4.10 \mathrm{bc}$ \\
\hline
\end{tabular}




\begin{tabular}{|l|l|l|l|l|l|l|l|}
\hline $3 \% \mathrm{LF}$ & $8.21 \mathrm{~d}$ & $8.14 \mathrm{c}$ & $8.04 \mathrm{c}$ & $8.00 \mathrm{bc}$ & $7.99 \mathrm{bc}$ & $4.59 \mathrm{a}$ & $4.15 \mathrm{~b}$ \\
\hline Control & $8.11 \mathrm{e}$ & $8.10 \mathrm{~cd}$ & $7.96 \mathrm{~d}$ & $7.91 \mathrm{~d}$ & $7.71 \mathrm{e}$ & $4.56 \mathrm{~b}$ & $4.53 \mathrm{a}$ \\
\hline
\end{tabular}

Means followed by the same letter are not significantly different; for a given column $(P<0.05)$.

Skim milk powder addition to distilled water $(9.5 \%(\mathrm{w} / \mathrm{v})$; stirring for $20 \mathrm{~min}$ followed by cooling at $4{ }^{\circ} \mathrm{C}$ for $24 \mathrm{~h}$ Supplementation with lentil flour (LF; $1-3 \%$ $\mathrm{w} / \mathrm{v}$ ) or skim milk powder (SM; $1-3 \% \mathrm{w} / \mathrm{v})$
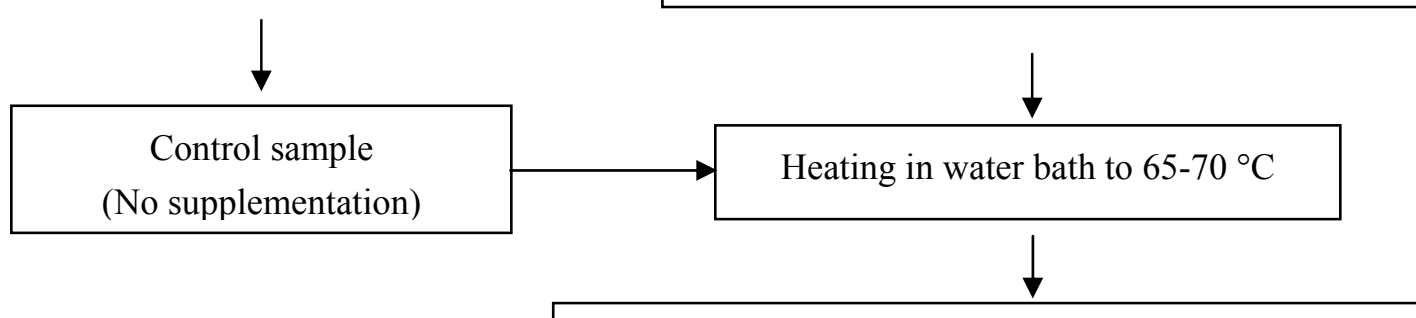

Homogenization with Polytron (Kinematica, AG, Switzerland) for $3 \mathrm{~min}$ at $2500 \mathrm{rpm}$

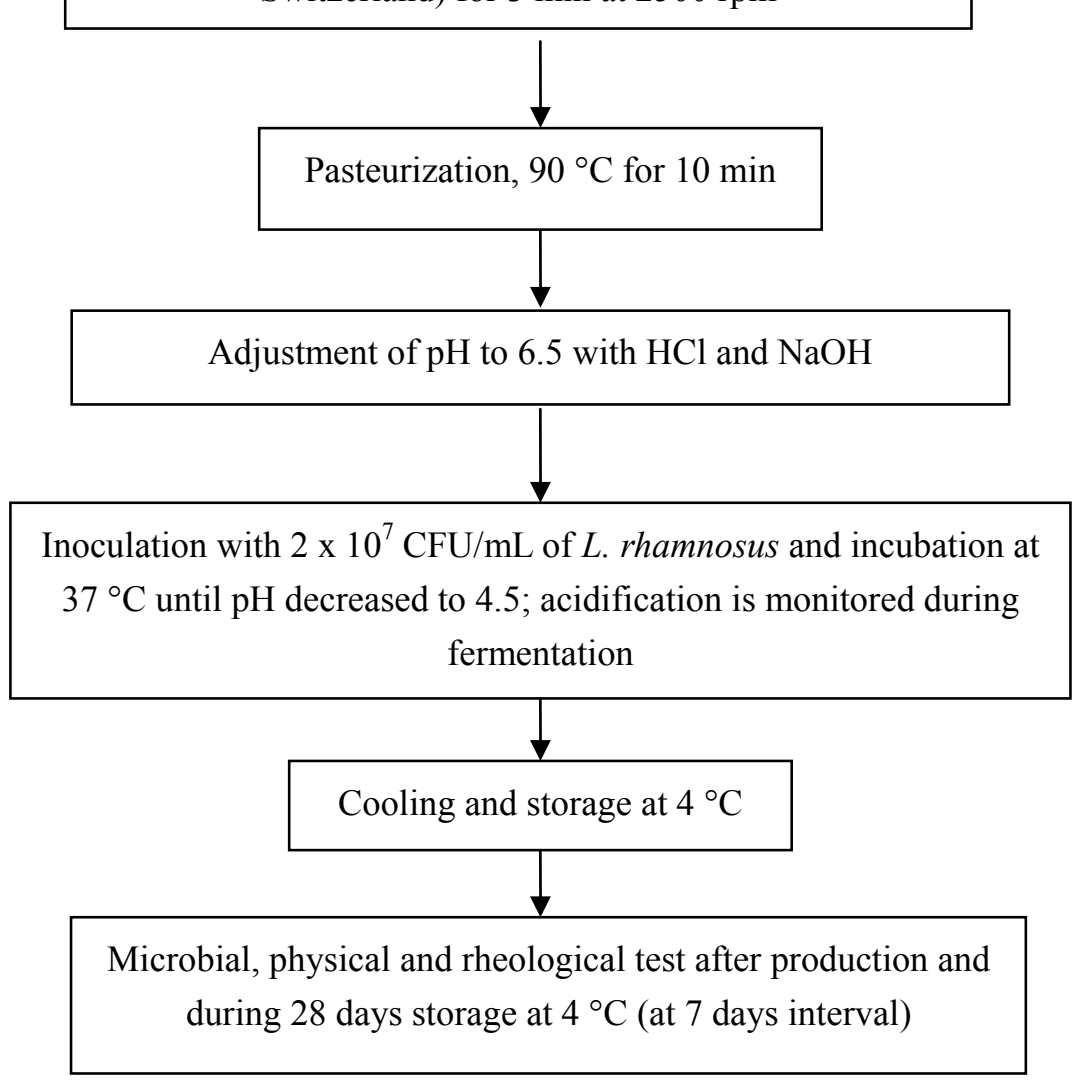

Figure 1. Schematic presentation of the process used for the preparation of L.rhamnosus probiotic beverage supplemented with skim milk powder (SM) or lentil flour (LF) and the control sample 


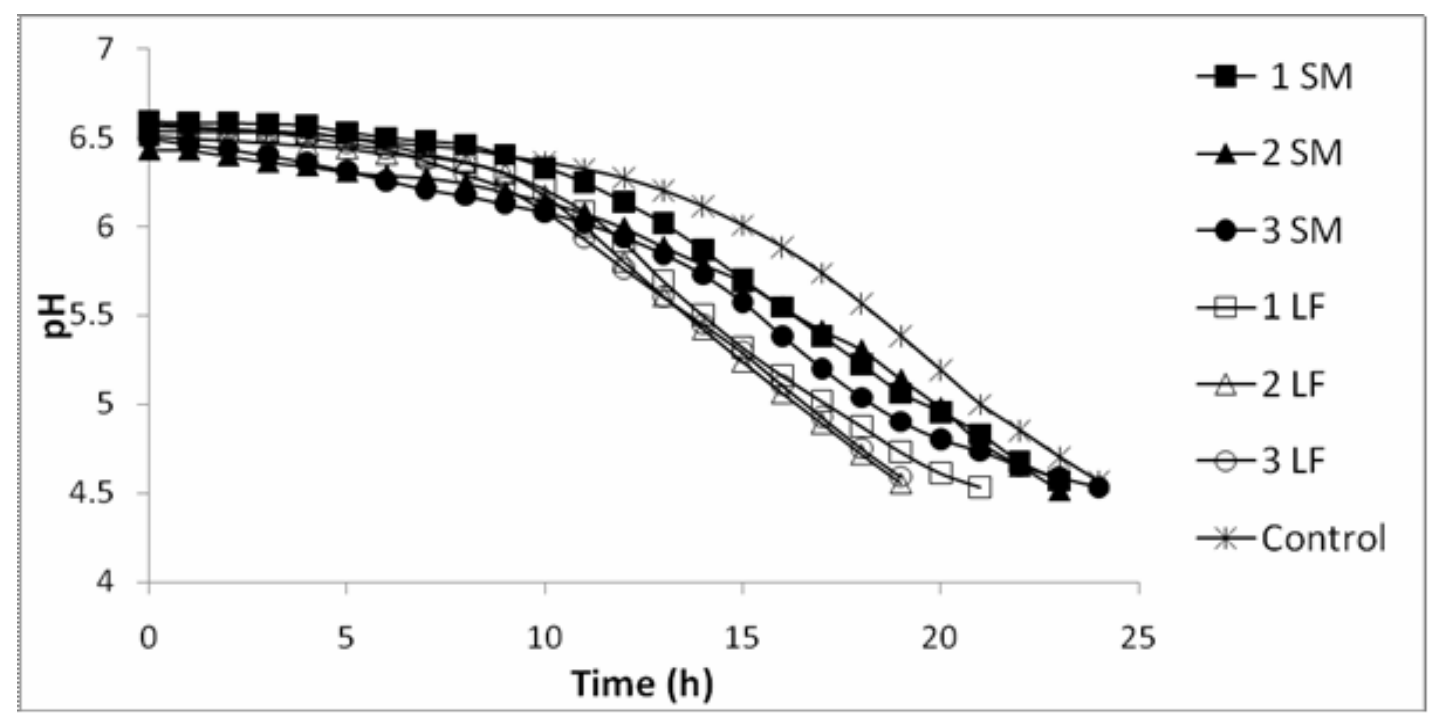

Figure 2. Acidification trend of skim milk (SM) containing L. rhamnosus AD200 supplemented with 1 to 3\% lentil flour (1 LF, 2 LF and 3 LF - treatments) or 1-3\% skim milk (1 SM, 2 SM and 3 SM - treatments)

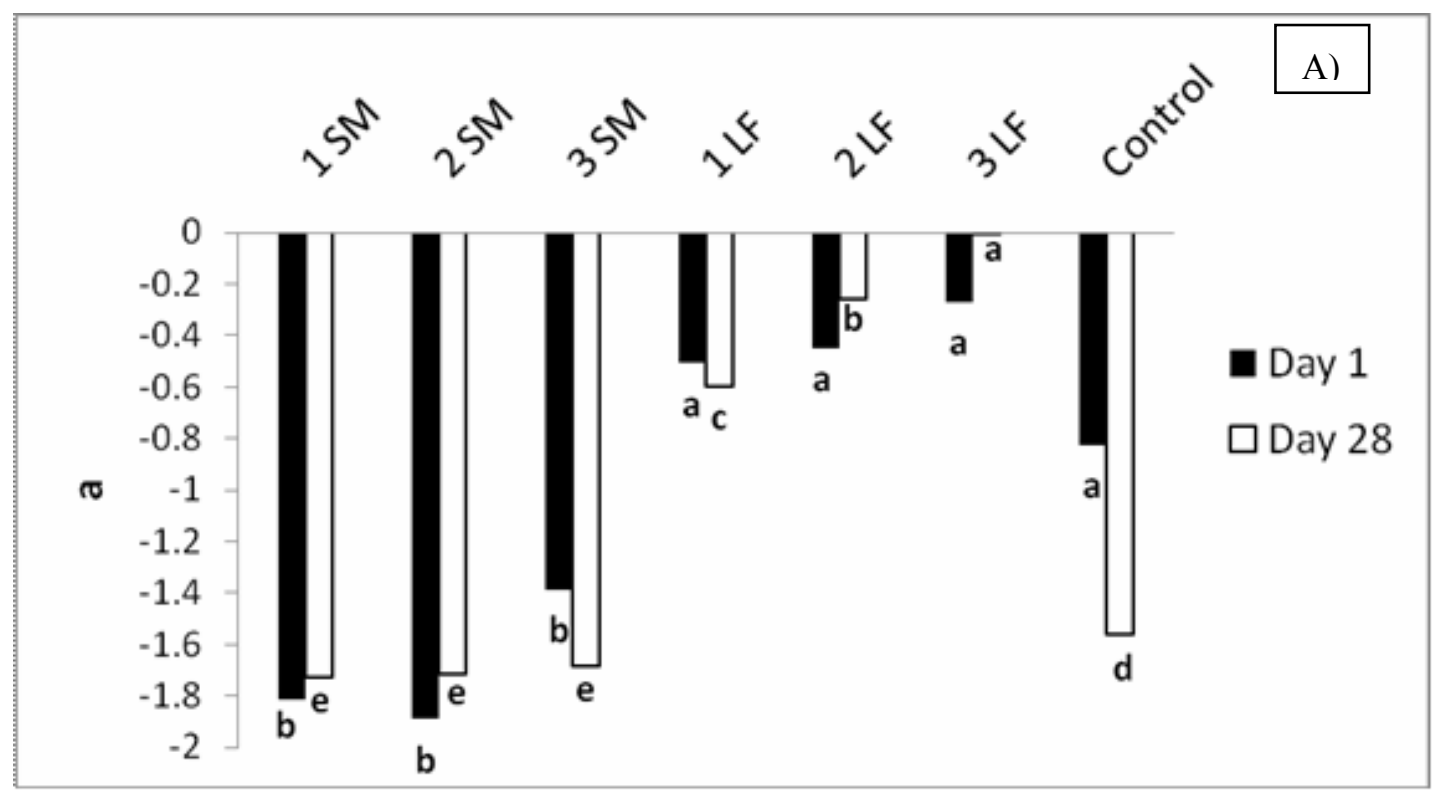



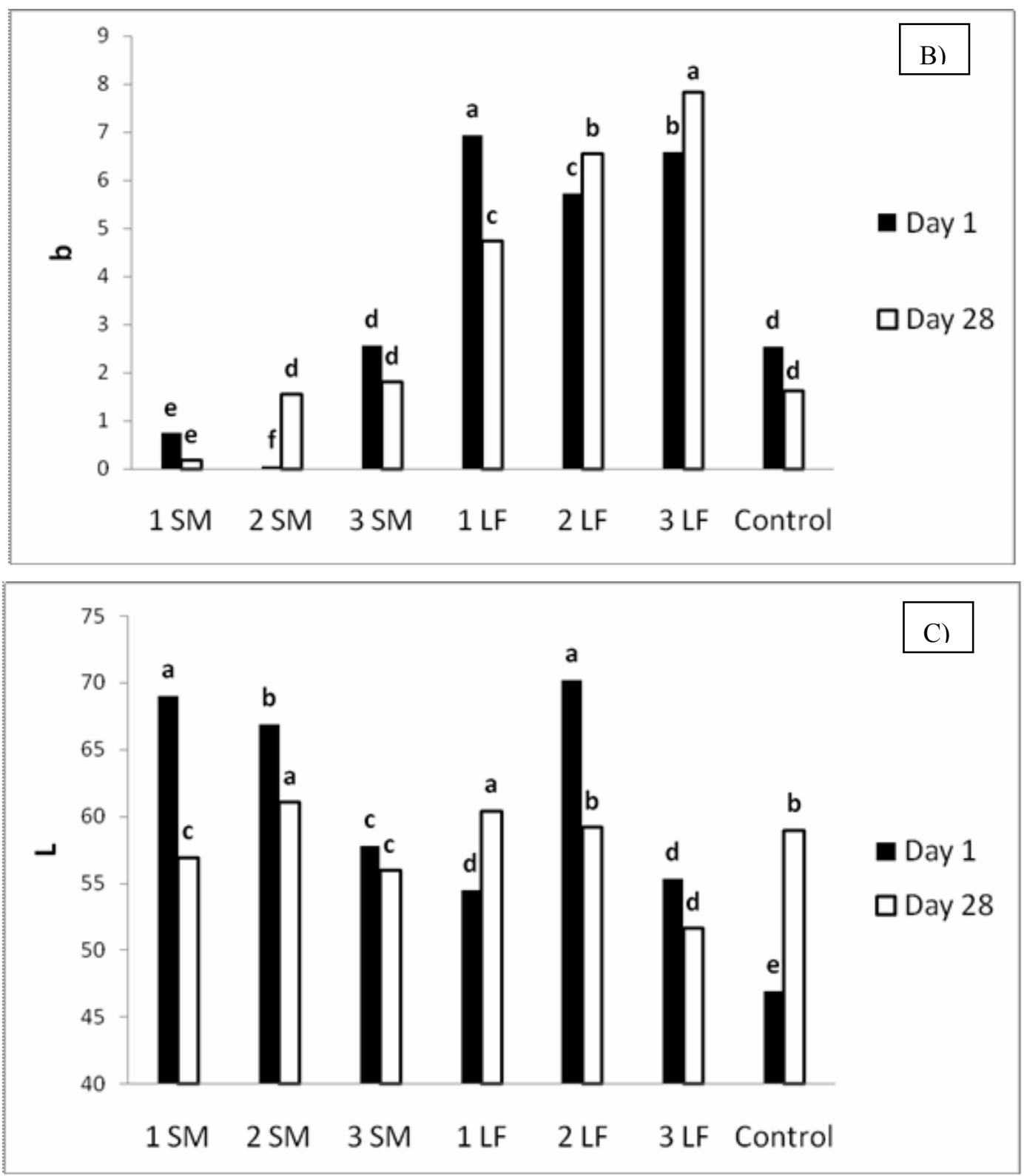

Figure 3. Color profile of probiotic beverages supplemented with 1-3\% lentil flour or 1-3\% skim milk and control sample (no supplementation) after production and after 28 days storage (SM: skim milk, LF: lentil flour; a (a value) +ve red, -ve green; b (b value) +ve yellow, -ve blue; c (L value): -0 to 100, black to white), means followed by the same letter are not significantly different $(P<0.05)$ 


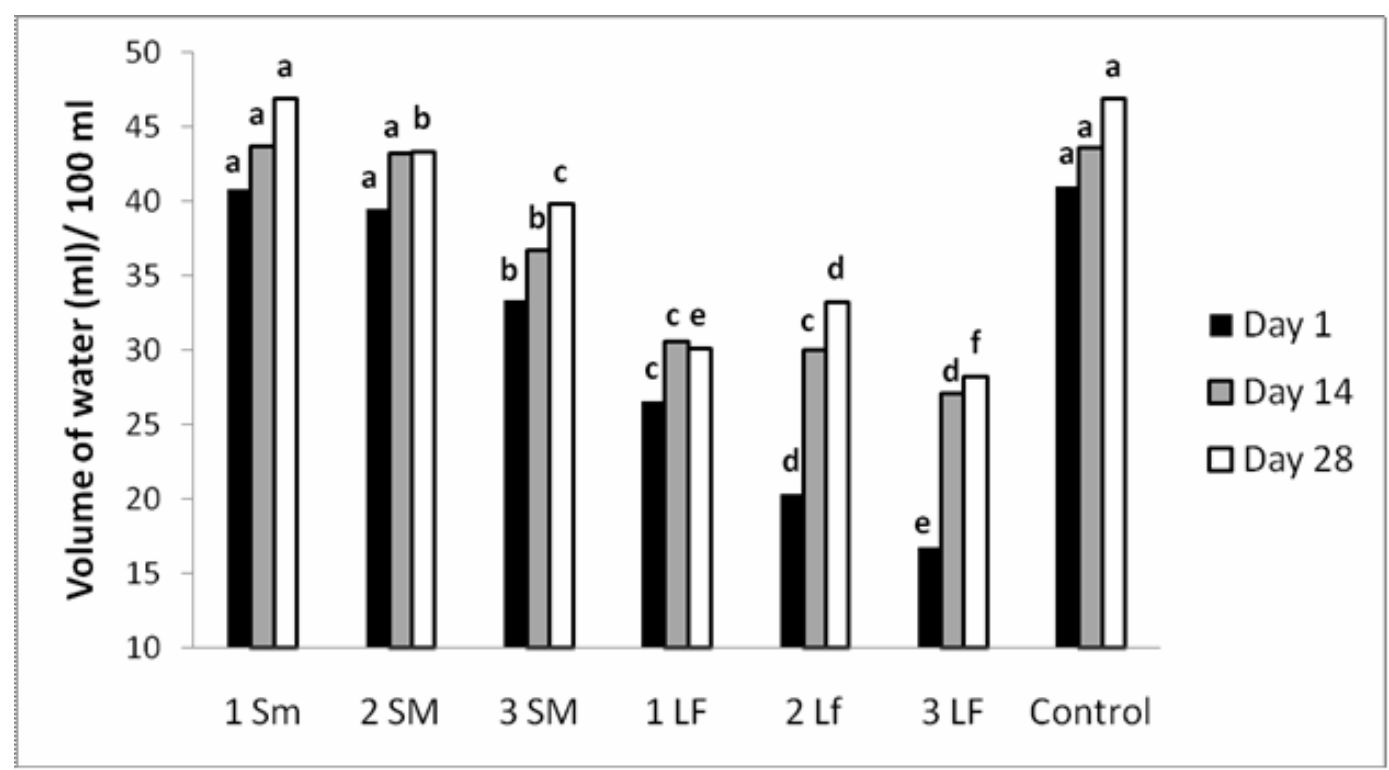

Figure 4. Syneresis in probiotic beverages supplemented with 1-3\% lentil flour, 1-3\% skim and control sample (no supplementation) during 28 day storage (SM: skim milk, LF: lentil flour), means followed by the same letter are not significantly different $(P<0.05)$ 

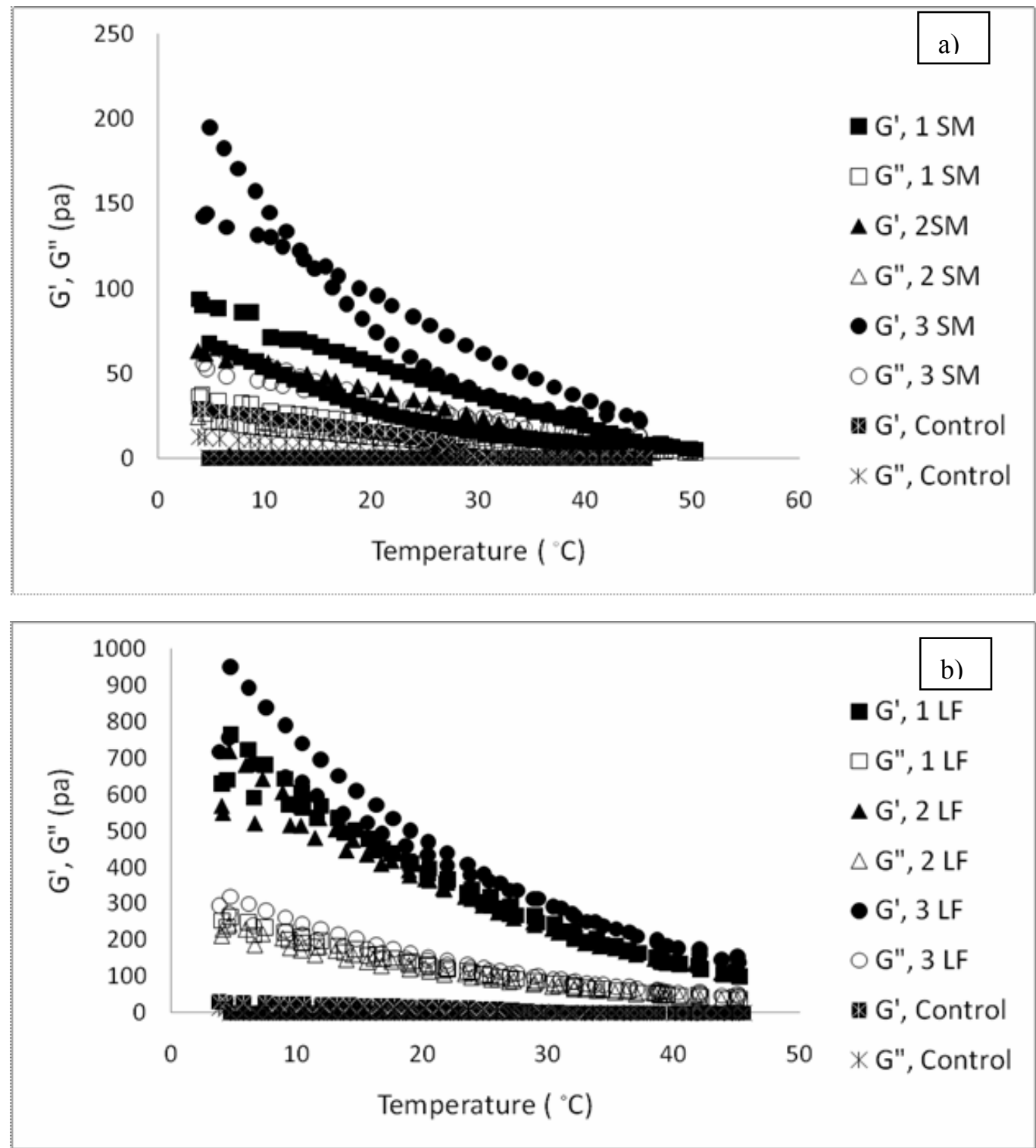

Figure 5. Storage $\left(G^{\prime}\right)$ (elasticity) and loss $\left(G^{\prime \prime}\right)$ (viscosity) moduli of fermented probiotic beverage products supplemented with (a) 1-3\% skim milk and (b) 1-3\% lentil flour heated from 4 to $50{ }^{\circ} \mathrm{C}$ and cooled back from 50 to $4{ }^{\circ} \mathrm{C}$ at day 1 , (SM : skim milk, LF: lentil flour) 

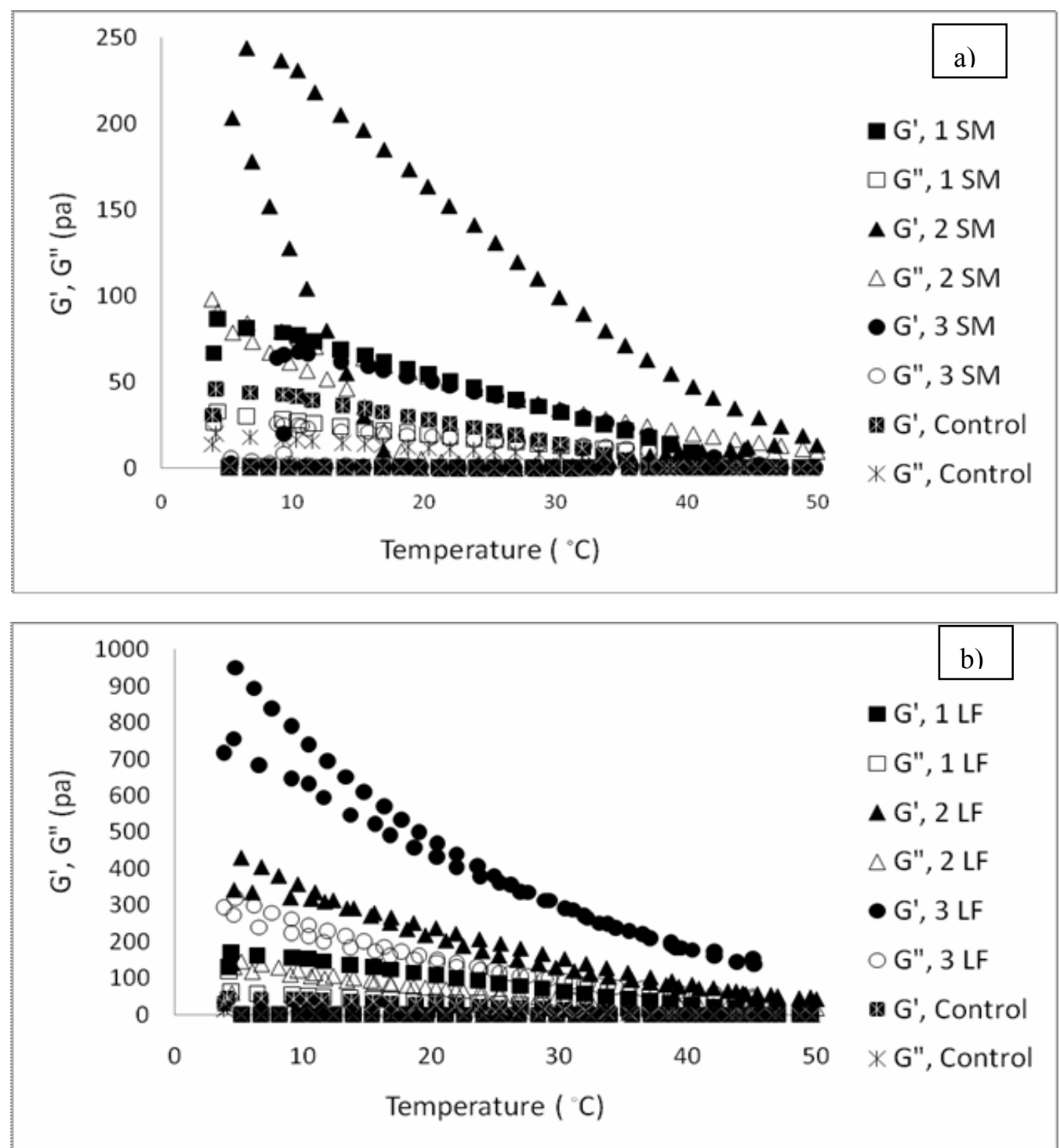

Figure 6. Storage $\left(G^{\prime}\right)$ (elasticity) and loss $\left(G^{\prime \prime}\right)$ (viscosity) moduli of fermented probiotic beverage products supplemented with (a) 1-3\% skim milk and (b) 1-3\% lentil flour heated from 4 to $50{ }^{\circ} \mathrm{C}$ and cooled back from 50 to $4{ }^{\circ} \mathrm{C}$ after 14 days of storage, (SM : skim milk, LF: lentil flour) 

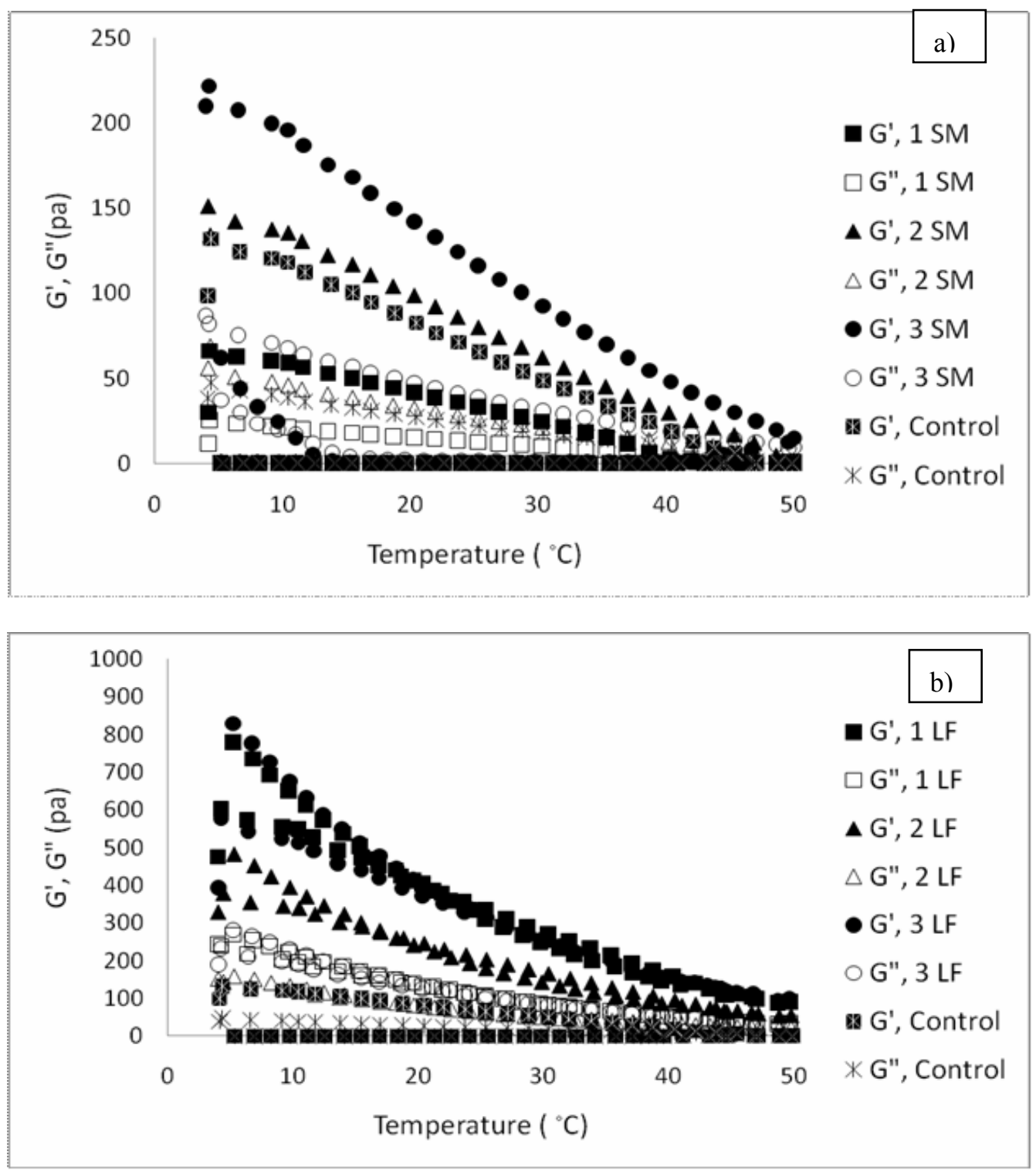

Figure 7. Storage $\left(\mathrm{G}^{\prime}\right)$ (elasticity) and loss $\left(\mathrm{G}^{\prime \prime}\right)$ (viscosity) moduli of fermented probiotic beverage products supplemented with (a) 1-3\% skim milk and (b) 1-3\% lentil flour heated from 4 to $50{ }^{\circ} \mathrm{C}$ and cooled back from 50 to $4{ }^{\circ} \mathrm{C}$ after 28 days of storage, (SM : skim milk, LF: lentil flour) 